'Universidad de los Andes. Hospital Militar. Santiago, Chile. ${ }^{2}$ Servicio de Inmunoreumatología. Hospital Militar. Santiago, Chile. ${ }^{3}$ Unidad de tratamiento intermedio. Hospital Militar. Santiago, Chile. aBecaria de Medicina Interna. Fuente de apoyo financiero: ninguna.

Recibido el 4 de abril de 2016, aceptado el 25 de noviembre de 2016.

Correspondencia a: Estefanía Palma. Celular: 7-7476878 epalma@miuandes.cl

\section{Tormenta de citoquinas: reacción adversa inhabitual por rituximab. Caso clínico}

\author{
ESTEFANÍA PALMA ${ }^{1, a}$, VICENTE GONZÁLEZ², \\ DANIELA GRÜNHOLZ², MARÍA LANDAETA², MARÍA MALLEA ${ }^{3}$, \\ JOSÉ PÉREZ ${ }^{3}$, TOMÁS ARMSTRONG ${ }^{3}$
}

\section{Shock as an adverse reaction to rituximab. Case report}

Rituximab is a plausible alternative first-line treatment of ANCA-associated vasculitis. Adverse effects related to its infusion are common and usually have a benign course. However, there have been reports of refractory cardiogenic shock simulating septic shock. We report an 81-year-old male with the diagnosis of ANCA associated vasculitis. Rituximab $500 \mathrm{mg}$ was administered intravenously for a relapse. The infusion proceeded without incident. However, 24 hours after its administration the patient began with fever, chills, coughing and strong malaise. The patient was transferred to the critical patient unit where a septic shock was suspected and resuscitative measures were started. However, the fast response to moderate doses of vasoactive drugs and complementary tests did not support an infectious etiology for the shock. Antimicrobials were discontinued and systemic corticosteroids were maintained, achieving remission of the symptoms. Shock as an unusual adverse reaction to Rituximab was suspected.

(Rev Med Chile 2017; 145: 260-263)

Key words: Anti-Neutrophil Cytoplasmic Antibody-Associated Vasculitis; Drug-Related Side Effects and Adverse Reactions; Rituximab; Shock.
$\mathrm{E}$ 1 rituximab es un anticuerpo monoclonal quimérico anti-CD20 utilizado en el tratamiento de neoplasias hematológicas (linfoma no Hodgkin, leucemia linfocítica crónica), artritis reumatoide refractaria y manifestaciones graves del lupus eritematoso sistémico, entre otras.

En los últimos años, en búsqueda de terapias tan efectivas como la ciclofosfamida, pero con un perfil de seguridad más favorable, este medicamento se ha establecido como opción terapéutica en vasculitis asociadas a anticuerpos anticitoplasma de neutrófilos (ANCA). El estudio RAVE evaluó el tratamiento de inducción a la remisión con rituximab en 197 pacientes, demostrando no inferioridad con respecto a ciclofosfamida y con un perfil de seguridad similar. Así, el rituximab se ha situado como tratamiento de primera línea en vasculitis asociadas a ANCA de reciente diagnóstico y en recaídas.

Los efectos adversos descritos son frecuentes, pero la mayoría leves: cefalea, fiebre, calofríos, náuseas, rinitis, prurito, astenia y urticaria. Se presentan principalmente durante la primera administración, ya sea durante la infusión o pocas horas posterior a esta (aunque se han reportado hasta 30 días después).

Sin embargo, en pacientes portadores de enfermedades hematológicas se han descrito reacciones severas, tales como broncoespasmo, insuficiencia respiratoria aguda e hipotensión. La reacción llamada "tormenta de citoquinas" ha sido escasamente documentada en la literatura en pacientes portadores de vasculitis.

A continuación, describimos el caso de un 
paciente portador de vasculitis asociada a ANCA, quien a las $24 \mathrm{~h}$ post administración de rituximab desarrolla un shock sin causa aparente. Un enfrentamiento clínico estructurado nos llevó al diagnóstico presuntivo final, que constituye el primer caso reportado en la literatura en que una tormenta de citoquinas se asocia al uso de rituximab en vasculitis.

\section{Caso clínico}

Paciente sexo masculino, 81 años, portador de poliartritis simétrica de manos, que en un inicio fue catalogado como artritis seronegativa; años más tarde se agregó cuadro de dolor urente y parestesias en extremidades inferiores. Se repitió el estudio, y dado MPO (+) y biopsia de nervio sural compatible con vasculitis de vaso pequeño, se estableció el diagnóstico de vasculitis asociada a ANCA (MPO (+)), con compromiso pulmonar (Usual Interstitial Pneumonia [UIP], demostrado por tomografía axial computada [TAC]), articular y neurológico. Además, con antecedente de cardiopatía coronaria, insuficiencia cardíaca CF I-II y enfermedad renal crónica (ERC) etapa 3. Desde el punto de vista cardiológico, el paciente había presentado un síndrome coronario agudo en el año 2012, cuya coronariografía mostraba oclusión del ramo marginal y estenosis no significativa de vasos principales. Ecocardiograma con hipertrofia del ventrículo izquierdo y leve hipertensión de la arteria pulmonar. Al momento del diagnóstico se intentó usar ciclofosfamida oral, sin embargo, el paciente presentó pancitopenia severa, por lo que se suspendió.

En tratamiento de mantención por 4 años con prednisona $5 \mathrm{mg} /$ día y azatioprina $50 \mathrm{mg} /$ día. Estable y asintomático. Las semanas previas a la última consulta se diagnosticó reactivación de su vasculitis, caracterizada por reinicio del dolor y parestesias en extremidades inferiores, intenso livedo reticularis $y$ aumento progresivo de VHS y PCR, decidiéndose inducción de la remisión con rituximab (no se tomó nueva biopsia). Exámenes previos al procedimiento: Hemoglobina 13,9 g/ dL, glóbulos blancos $12.300 / \mathrm{mm}^{3}$, VHS $64 \mathrm{~mm} / \mathrm{h}$, creatinina $1,39 \mathrm{mg} / \mathrm{dL}$, nitrógeno ureico $23 \mathrm{mg} / \mathrm{dL}$, glicemia $101 \mathrm{mg} / \mathrm{dL}$, albúmina $4 \mathrm{~g} / \mathrm{dL}$, colesterol total $145 \mathrm{mg} / \mathrm{dl}$, bilirrubina total $0,5 \mathrm{mg} / \mathrm{dL}$.

Se hospitalizó para su administración, preme- dicándose con metilprednisolona (125 mg), transcurriendo sin incidentes y enviado a su domicilio. Sin embargo, aproximadamente a las $24 \mathrm{~h}$ de su infusión inició fiebre hasta $39,8^{\circ} \mathrm{C}$, dificultad respiratoria, tos con expectoración mucopurulenta y marcado compromiso del estado general.

Consultó al servicio de urgencias, donde se evidenció febril $\left(38,3{ }^{\circ} \mathrm{C}\right)$, hipotenso (PAM 49 $\mathrm{mmHg}$ ), desaturando $89 \%$ ambiental y polipneico (FR 29x'). Al examen físico se constató mal perfundido y con uso de musculatura accesoria. Exámenes de laboratorio: Hemoglobina $14,4 \mathrm{~g} / \mathrm{dL}$, leucocitos $5.200 / \mathrm{mm}^{3}$, proteína C reactiva $177 \mathrm{mg} / \mathrm{L}$, gases arteriales: $\mathrm{pH} 7,49 ; \mathrm{pO}_{2}$ $53 \mathrm{mmHg} ; \mathrm{HCO}_{3} 19 \mathrm{mEq} / \mathrm{L} ; \mathrm{SatO}_{2}$ 91\%; PaFi 254, lactato arterial $23 \mathrm{mmol}$, troponina $0,07 \mathrm{ng} / \mathrm{mL}$, BNP $254 \mathrm{ug} / \mathrm{l}$, creatinina $1,87 \mathrm{mg} / \mathrm{dL}$, nitrógeno ureico $33 \mathrm{mg} / \mathrm{dL}$. Radiografía de tórax: cardiomegalia, hallazgos secundarios a UIP, sin signos de condensación, congestión ni derrame pleural evidentes. Electrocardiograma: ritmo sinusal, sin alteraciones.

Se volemizó vigorosamente, persistiendo hipotenso, por lo que ingresó a UTI para manejo. Se tomaron hemocultivos y se inició empíricamente tratamiento antimicrobiano con moxifloxacino (completa 10 días) y oseltamivir (completa 5 días). Además, se inició uso de vasoactivos y corticoides en dosis de estrés.

Evolucionó con requerimientos de noradrenalina hasta $0,1 \mathrm{mcg} / \mathrm{kg} / \mathrm{min}$, que se lograron suspender a las $12 \mathrm{~h}$. Se obtuvo muestra para panel viral y PCR viral (-), hemocultivos (-), urocultivo (-) y ausencia de leucocitosis en mediciones seriadas. TAC tórax no presentaba focos de condensación ni derrame pleural asociado (Figura 1).

Evolucionó con rápida remisión de todos los síntomas y en menos de 48 h se trasladó a unidad de menor complejidad.

\section{Discusión}

En los últimos años, el rituximab se ha situado como terapia de primera línea en vasculitis asociadas a ANCA y ha demostrado ser no inferior y con un perfil de seguridad similar a ciclofosfamida.

Las reacciones adversas más frecuentes son en relación a su administración, leves y transitorias, destacando fiebre, calofríos, mialgias, cefalea, náuseas, vómitos, entre otras. Son particularmente 


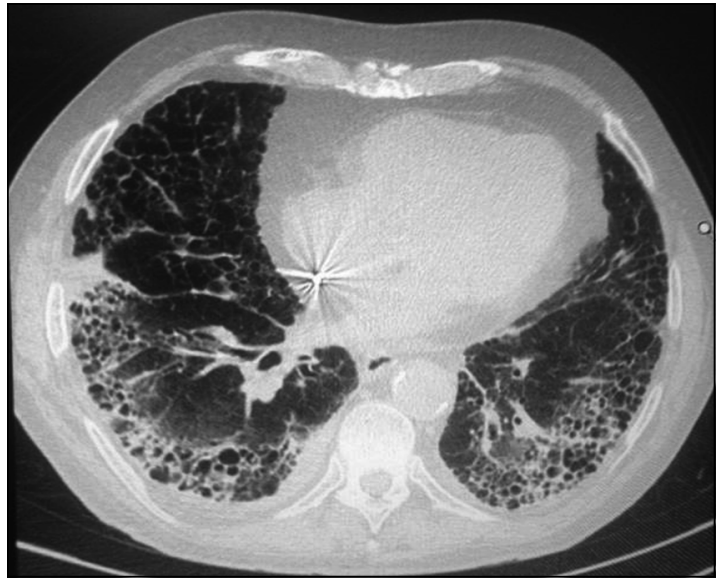

Figura 1. TAC de tórax, corte transversal. Sin evidencias de focos de condensación. Destacan signos de fibrosis tipo UIP, opacidad en vidrio esmerilado en lóbulo superior derecho y engrosamiento de las paredes quísticas en ambas bases pulmonares, sugerentes de un proceso inflamatorio sobreagregado: infeccioso vs reactivación de vasculitis.

frecuentes en neoplasias hematológicas (77-94\% vs $12 \%$ en vasculitis) y durante la primera exposición al fármaco.

No obstante, $10 \%$ de los pacientes pueden desarrollar síntomas graves, tales como hipotensión, infarto al miocardio, fibrilación ventricular, shock cardiogénico, broncoespasmo, angioedema y síndrome de distrés respiratorio agudo. La etiología de las complicaciones cardiovasculares y pulmonares aún es incierta, pero se postula que podrían ser secundarias a la llamada "tormenta de citoquinas", debida a una liberación masiva de IFN- $\gamma$, IL-6, IL-8, IL-10 $0^{2-5}$.

Datos post marketing y de registros indican que las reacciones cardiopulmonares fatales ocurren en $0,04-0,07 \%$ de los pacientes, asociado a la primera infusión en $80 \%$ de los casos. La literatura habitualmente reporta tales efectos dentro de 30 a $120 \mathrm{~min}$ de la infusión. Sin embargo, en nuestro paciente aún es planteable, tal como describieron Wuet al. en el año 2007, donde un grupo de pacientes tratados con rituximab presentó síntomas hasta 24 h post infusión ${ }^{6-8}$.

El caso clínico describe un paciente que a las $24 \mathrm{~h}$ post administración de rituximab desarrolla un shock sin etiología clara. Inicialmente se plantea como séptico de foco pulmonar, sin embargo, la rápida respuesta clínica, estudios microbio- lógicos negativos, ausencia de leucocitosis en mediciones seriadas, de imágenes nuevas en TAC y de elementos para postular shock hipovolémico o cardiogénico, hicieron plantear una reacción adversa por rituximab, denominada tormenta de citoquinas. Dado que la presentación no fue inmediata o hasta $1 \mathrm{~h}$ posterior, la anafilaxia era menos probable.

El cuadro de liberación masiva de citoquinas es un fenómeno muy infrecuente, pero cuya asociación al shock fue reportada por Gutiérrez et al, quienes describen el primer caso de shock refractario letal a rituximab. Este se asoció a niveles elevados de IL-6 y de IL-8, similar a lo observado en pacientes con rápida instalación de shock séptico?.

El mecanismo de producción de liberación de citoquinas se ha relacionado con el entrecruzamiento del rituximab con las células CD20+, la subsecuente activación y las lisis de las células blanco, y, finalmente, la liberación de citoquinas (como IFN- $\gamma$, IL 6, IL 8 y TNF $\alpha$ ), luego de la administración del anticuerpo monoclonal. Además, el reclutamiento de los macrófagos contribuye a la liberación de citoquinas por interacción entre los receptores Fc de los macrófagos y la porción Fc del anticuerpo monoclonal ${ }^{10}$.

Por último, cabe mencionar que habría sido interesante descartar una neoplasia subyacente, considerando que la tormenta de citoquinas se ha asociado principalmente a pacientes oncológicos, y el riesgo aumentado propio del paciente (edad y condición de portador de vasculitis ANCA p, la que se ha asociado con mayor frecuencia a neoplasias).

\section{Conclusión}

Las reacciones severas al rituximab son poco frecuentes, pero potencialmente letales. Una monitorización estricta durante y posterior a la infusión, la suspensión de hipotensores las horas previas y la premedicación, podrían disminuir la incidencia de eventos adversos. Además, es fundamental educar a los pacientes en relación a consultar precozmente al servicio de urgencia.

Según nuestra revisión, existen escasos casos descritos de esta complicación en pacientes reumatológicos, lo que hace que el caso presentado sea de particular interés. 


\section{Referencias}

1. Emery P, Fleischmann R, Filipowicz-Sosnowska A, Schechtman J, Szczepanski L, Kavanaugh A, et al. The efficacy and safety of rituximab in patients with active rheumatoid arthritis despite methotrexate treatment: results of a phase IIB randomized, double-blind, placebo-controlled, dose ranging trial. Arthritis Rheum 2006; 54 (5): 1390-400.

2. O’Brien S, Kantarjian H, Thomas D, Giles F, Freireich E, Cortés J, et al. M. Rituximab dose-escalation trial in chronic lymphocytic leukemia. J Clin Oncol 2001; 19: 2165-70.

3. Plosker GL, Figgit DP. Rituximab: a review of its use in nonhodgkin's lymphoma and chronic lymphocytic leukaemia. Drugs 2003; 63: 803-43.

4. Ghielmini M, Schimtz S, Burki K, Pichert G, Betticher $\mathrm{D}$, Stupp R, et al. The effect of rituximab on patients with follicular and mantle-cell lymphoma. Ann Oncol 2000; 11: S123-6.

5. Bugelski P, Achuthanandam R, Capocasale R, Treacy G, Bouman-Thio E. Monoplano antibody-induced cytokine-release syndrome. Expert Rev Clin Immunol 2009; 5 (5): 499-521.
6. Kunkel L, Wong A, Maneatis T, Nickas J, Brown T, Grillo-López A, et al. Optimizing the use of rituximab for treatment of B-cell non-Hodgkin's lymphoma: a benefit-risk update. Semin Oncol 2000; 27: 53-61.

7. Millward P, Bandarenko N, Chang P, Stagg K, Afenyi-Annan A, Hay S, et al. Cardiogenic shock complicates successful treatment of refractory thrombotic thrombocytopenia purpura with Rituximab. Transfusion 2005; 45: 1481-86.

8. Wu SJ, Chou WC, Ko BS, Tien HF: Severe pulmonary complications after initial treatment with Rituximab for the Asian-variant of intravascular lymphoma. Haematologica 2007; 92: 141-2.

9. Gutiérrez A, Rodríguez J, Martínez J, Amezaga R, Ramos R, Galmes B, et al. Pathogenic study of anti-CD20 infusion-related severe refractory shock in diffuse large B-cell lymphoma. Leukemia \& Lymphoma 2006; 47 (1): 111-5.

10. Makino K, Nakata J, Kawachi S, Hayashi T, Nakajima A, Yokoyama M. Treatment strategy for reducing the risk of rituximab-induced cytokine release syndrome in patients with intravascular large B-cell lymphoma: a case report and review of the literature. J Med Case Rep 2013; 7: 280. 